\title{
Incubation Process Case Study
}

\author{
Jeffrey Shepard Survey ${ }^{1, *}$ \\ ${ }^{1}$ Saybrook University, Oakland, CA, USA \\ *Correspondence: Saybrook University, Oakland, CA, USA. E-mail: jshepard@saybrook.edu
}

Received: April 24, 2018

Accepted: May 11, 2018 Online Published: July 23, 2018

doi:10.5430/mos.v5n3p43

URL: https://doi.org/10.5430/mos.v5n3p43

\begin{abstract}
The purpose of this case study is to create a profile of business incubators by exploring various aspects concerned with their operations. While tracing the history, development and current practices of business incubators, the aspects explored include the identification of: the nature of clients served, incubator mission, incubator staffing/personnel, incubator management, incubator resources, and incubator facilities/technology. The main motivation behind this case study is to compile an exhaustive profile of business incubators into one paper.

This case study mainly utilized secondary research. By using questionnaires, a survey conducted among managers of selected business incubators in the United States was done. The exploratory nature of this study prompted the use of open ended questions.

Findings concerning incubator mission are that current incubators mainly provide professional services of increased complexity as opposed to earlier incubators. Regarding personnel, modern incubators have formal organization structures characterized by the aspect of co-learning. While earlier incubators primarily offered cheap rental space, modern incubators share resources via a complex network of virtual connectivity. On technology, sophisticated technological communication interfaces such as the internet are vital, previous incubators relied on outdated technology. Concerning management, modern incubators require highly adaptive managers capable of addressing specific needs due to the constantly changing business environment. Other findings include the fact that clients are predominantly small business owners and students. Further, managers mainly provide direct services to clients such as mentoring, coaching, and training.
\end{abstract}

Keywords: business incubators, incubator management, incubator mission, modern incubators

\section{Survey findings}

\subsection{Incubator Managers (Client's-Served)}

Here the respondents were asked, on the basis of their experience as incubator managers, to identify the most common background of their clients (or "incubates") prior to incubation. The figure shows that the most commonly cited pre-incubation occupations were "small business owners" (59\%) and "students" (31\%). After these, "currently working" and "non-student, non-business owner" choices occurred with the next highest level of frequency (19\% and $17 \%$, respectively). Lastly, "non-student" and "unemployed" respectively received $7 \%$ and $6 \%$. Many respondents $(81 \%)$ selected only one choice, suggesting they seek to identify only the single most common background. In the opposite extreme, $6 \%$ of the respondents selected four or more answers.

The number of clients served by a given business incubator is indicative of its relative size. For the purpose of this study, the size was categorized as large (with over 15 clients) or small (with 15 clients or less), while only $17 \%$ of the respondents associated with smaller incubators identified students among their participants, nearly half (43\%) of the respondents associated with larger operations reported significant student participation. 


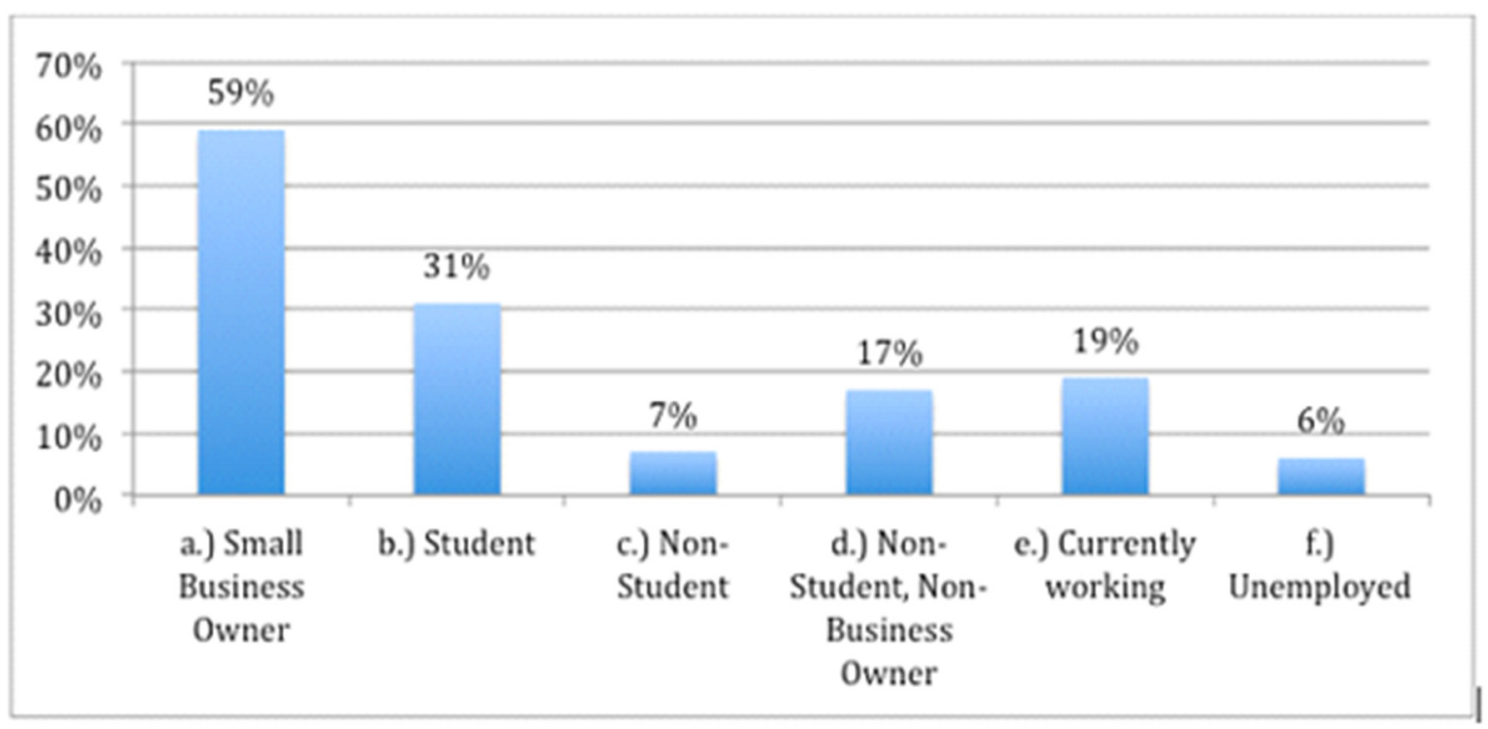

Figure 1. Incubator Managers

Respondents were asked to share information and views regarding a specific set of client characteristics. Two of these questions were descriptive, asking respondents to report whether and to what extent the clients they served were willing (a) to take risks; and (b) to adapt to changing business climates. The third question also asked respondents to identify specific traits they considered to be most crucial to client success in and beyond the incubation process. A total of $89 \%$ of respondents indicated that the majority of clients were risk-takers. Two of the forty-eight respondents belonging to this group qualified their responses by emphasizing that most participants were willing to take "reasonable risks," being "not risk-averse, but not reckless either." One respondent who did not opt to characterize the majority of incubates as "risk-takers" referred to clients instead as "optimistic risk managers." Another pointed out that although "every start-up situation involves risk, most entrepreneurs do everything they can to reduce the risk before launching." A total of $66 \%$ felt that most of their incubates were "very adaptive," while the remaining $34 \%$ considered a majority of their participants as being only "somewhat adaptive." It is worth noting that the latter response occurred at nearly twice that frequency (about 67\%) among respondents who also reported that a majority of incubates were not risk-takers. This may conceivably indicate that non-risk-taking incubator participants are also likely to be less adaptive than their risk-taking counterparts.

In addition to the descriptive questions described above, a third question asked respondents to identify traits they considered to be crucial to client success in growing a sustainable business. Four specific traits were provided for the respondents to choose from: (a) risk-taking; (b) the ability/willingness to overcome challenges; (c) organizational skills; and (d) leadership skills. Respondents were instructed to choose "all that apply." The most popularly identified trait associated with client success was the willingness and ability to overcome challenges, which was selected by $42 \%(n=34)$ of participating incubator managers (see Figure 2$)$. 


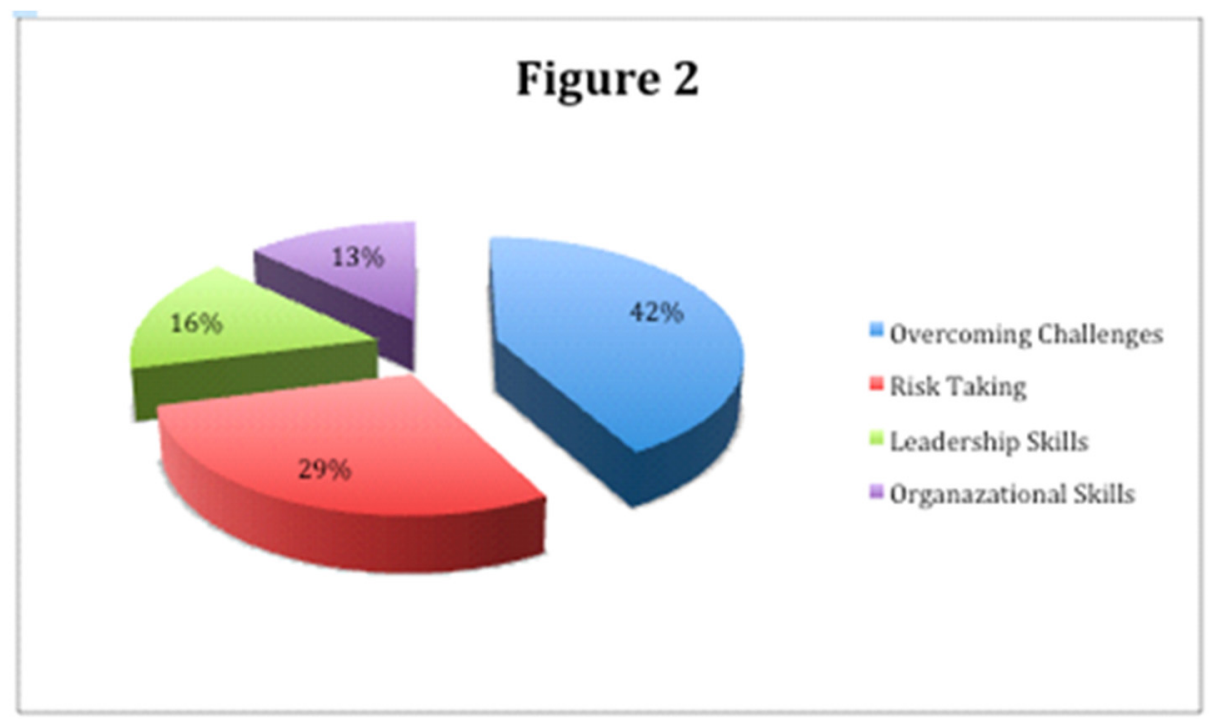

Figure 2. Successful Participants' Traits

Risk-taking came in second, with $29 \%$ support. Both organizational and leadership skills were chosen with the least frequency, at $13 \%$ and $24 \%$, respectively.

\section{Incubators}

\subsection{Mission}

The vast majority of incubator managers surveyed $(91 \%, \mathrm{n}=49)$ reported having an incubator mission statement. Of these, $65 \%(n=35)$ described their mission statement as being "extremely clear" and $24 \%(n=13)$ described it as "somewhat clear." Only one respondent reported having a mission statement that was "not clear at all." A total of 98\% of those who reported having a mission statement stated that the business plan and strategy that guided their incubator was supportive of that mission statement.

\subsection{Business Staffing}

Of interest in this study was how business incubator managers perceived the quality of their staff to operate an incubator and serve business clients. In answer to whether the staff was qualified to lead a business, a majority answered very qualified $(48 \%, \mathrm{n}=26)$ and qualified $(46 \%, \mathrm{n}=25)$. To the next question of whether they had the capacity to operate an incubator, a majority also affirmed that they were very qualified $(52 \%, \mathrm{n}=28)$ and qualified $(41 \%, \mathrm{n}=22)$.

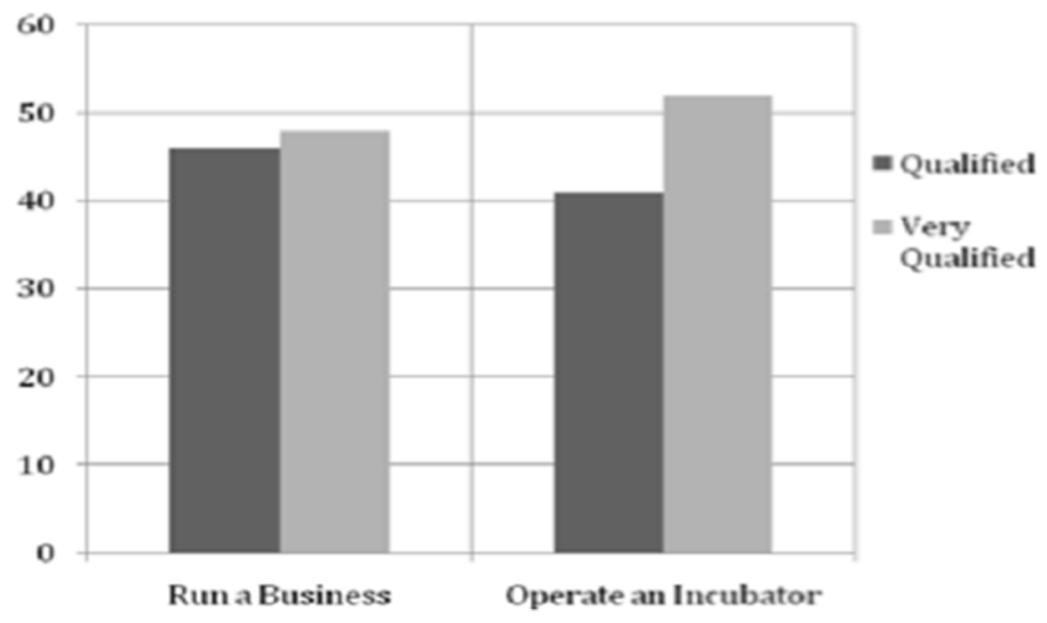

Figure 3. Business Staffing 


\subsection{Management}

In an open-ended format, the respondents were asked to identify specific activities that occupied the majority of their time as incubator managers. Of the 54 respondents, only 37 (about 69\%) provided viable answers to this question. While 39 responses were submitted, two were excluded in the course of analysis due to an extreme lack of specificity and/or clarity (i.e., Where the question was not answered in any tangible or useful way). The most commonly reported primary management activities were in the realm of direct client services. Of the 37 respondents who answered this question, $26(70 \%)$ cited direct engagement in these types of services as accounting for a significant portion of their time (see Figure 4). Respondents described such activities in terms of "mentoring," "advising," "counseling," "helping," and "working with" clients. One manager reported engaging in "client support" that was "similar to hotel hospitality." Others reported spending much of their time in "one-on-one" client meetings and sessions. The only two respondents who sought to provide an exact figure of the amount of time spent dealing directly with clients reported spending $40 \%$ and $60 \%$ of their time on such activities, respectively. Some reported, less precisely, spending "most" of their time so engaged, thereby making the data a little less informative than had been hoped. Most respondents in this group simply listed direct client services as the only type of (or as one of two) activities consuming a majority of their managerial schedules.

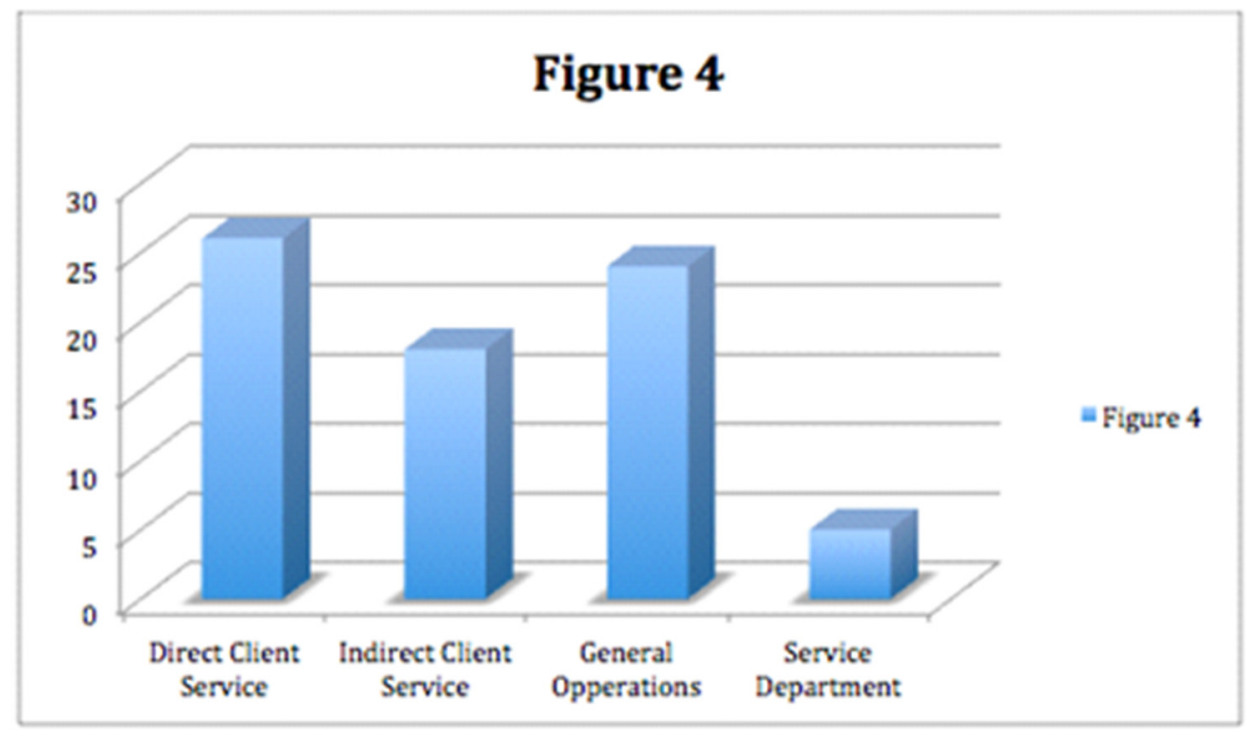

Figure 4. Management

Managers of larger-scale firms reported spending significant time in direct client services with the same frequency $(70 \%)$ as did those managing smaller-scale operations. This suggests that perhaps such "hands-on" involvement is not reflective of the type of "personal" service one might associate with smaller-scale businesses. Instead, direct involvement with participants may be typical of incubator management regardless of operational scale. Substantially fewer $(49 \%)$ of respondents reported that indirect, as opposed to direct, client services occupied a significant portion of their managerial schedules. 


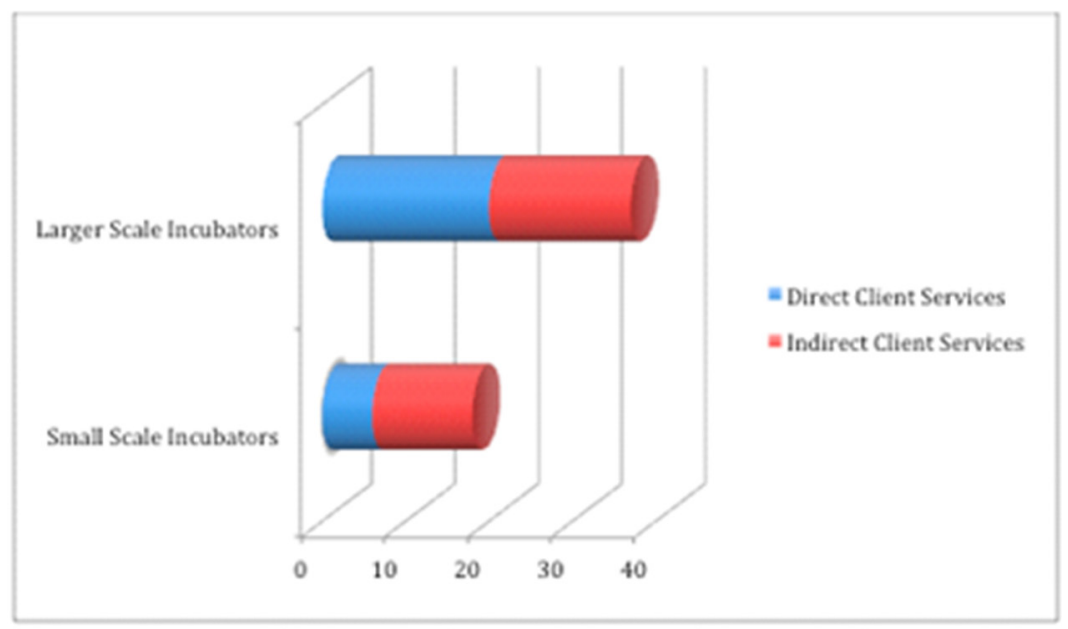

Figure 5. Client Services

Specifically, respondents associated with large-scale operations were twice as likely as those with smaller-scale firms to report that their time was spent on indirect client services ( $70 \%$ versus 35\%, respectively; see Figure 5). Apart from client services (direct and indirect), about 65\% (24 out of 37) of the respondents reported spending large portions of their time as incubator managers in the more traditional tasks associated with organizational management. Under this heading, the most commonly described activities are related to general operations. The fewest number of respondents (14\%) described engaging in the service development aspects of organizational management. In this group, one respondent commented that time was frequently spent "looking into ways for the incubator to advance." The remaining respondents offered more specific accounts of their service development efforts, describing two types of activities: (a) conducting industry research and (b) engaging in efforts to expand the incubator's available "external resources" and networking capacities. With reference to the latter, one respondent noted that significant time was spent "doing outreach and networking with other small business service providers and economic development partners." The fact that so few respondents included service development activities among the primary uses of their time as business managers is, from one perspective, puzzling. However, it is possible that the need for such development explains, in part, the high rate of direct and indirect client service involvement among incubator managers. Because the evolution of desired services is largely dependent on shifting client and client industry-specific needs, the "hands on" approach described by so many respondents may be crucial to an incubator's ongoing effort to offer innovative and competitive services. In this sense, managerial engagement in assessing and serving the needs of clients may be in itself the best strategic approach to maximally effective incubator service development.

The managers were asked in two survey questions about the advisory role of incubators and the enhancement of business acumen through business incubation. In the first of these, respondents were asked to rate the importance of the advisory role of their associated incubation programs on a four-point ordinal scale, from "not important" to "very important." Collected responses ranged from the second to fourth points, from "somewhat important" to "important" to "very important." Among these choices, the highest percentage $(61 \%)$ of respondents rated their incubator's advisory role as being "very important". Among the remaining responses, 30\% described it as being "important" and the remaining $9 \%$ indicated that they deemed it to be only "somewhat important." The fact that the vast majority of respondents (91\%) reported that the advisory role fulfilled by their respective incubators was either "important" or "very important" lends further credence to the notion that mentorship is of crucial value in present-day business incubation.

Respondents were elsewhere asked to indicate whether or not their associated incubator programs helped to accelerate the learning process in terms of business acumen. Responses to this question were overwhelmingly in the affirmative with $98 \%$ of the surveyed incubator managers agreeing on this point. Of the 37 respondents who answered this question, $18(49 \%)$ described incubates as gaining a better, more concrete sense of the skills and resources needed through mentorship and similar services. Several managers (38\%) also suggested that the incubation process offered participants a "reality check," as one respondent stated. Many respondents indicated that 
incubates were initially "over-confident" in the difficulties that would be involved in launching and growing their businesses. According to this group of incubator managers, clients tended to discover that "they don't know all they think they know," "there is more to it than they thought," "it wasn't that easy after all," or "it is not as easy as they think it is."

In a similar vein, some respondents pointed out the ways in which such a "reality check" paved the way for valuable growth. As one manager noted, once clients know to expect challenges, they are able to engage in "conscious (pro-active) decision making as opposed to reactive thinking," which again pointed to the entrepreneurial skill that is needed to run a successful business. A few $(\mathrm{n}=5)$ respondents suggested that the incubation process actually builds confidence among its clients. One manager indicated that the incubation "increases confidence by providing access to advice as needed." Another made specific reference to the benefits of the sort of business-to-business mentorship facilitated by incubation in this regard, noting that clients are "exposed to many different kinds of business owners and models that help them gain confidence in their own efforts." Two managers emphasized the ways in which incubation minimizes the sense of isolation frequently associated with early startups. In this sense, incubator clients took comfort in the fact "that they are not alone in this process," or, as another manager described, "They are not alone in the adventure." Managers saw their clients benefiting from their being with other start-up companies; not only was it considered as an advantage business-wise, it served as a confidence booster and discouraged a competitive environment.

\subsection{Facilities}

Surveyed incubator managers were asked to identify the types of facilities and facility-related services provided to incubate from a given list, with the option to specify any others not listed. Among those listed, the provision of Internet service was more frequently reported than any other type of service and facility, with an overwhelming $93 \%$ $(n=50)$ of respondent-associated incubators being identified as offering this vital business component (see Figure 7). The least frequently selected among the services and facilities listed were free accounting and legal services. These were reportedly provided by $15 \%$ and $19 \%$ of respondents' incubators, respectively. In addition to these services and facilities, $30 \%$ of the respondents listed others in the space provided.

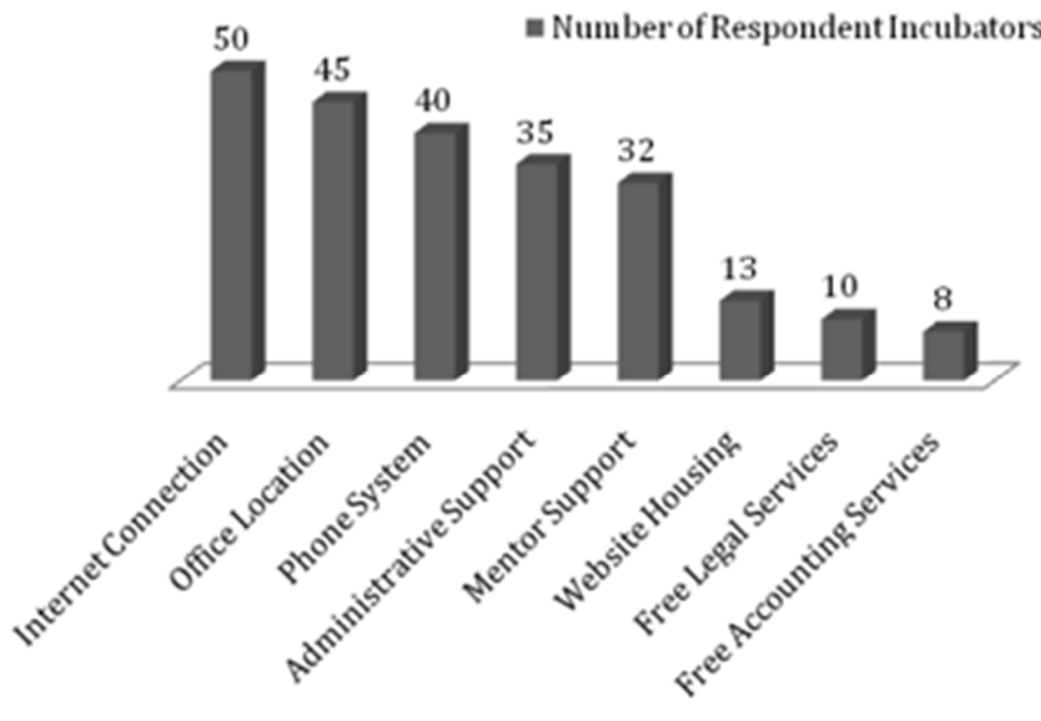

Figure 6. Facilities

\subsection{The Technology Involved}

In a series of two (somewhat overlapping) open-ended questions, managers were asked to (a) identify the specific technologies which were most "indispensable" to incubated businesses; and (b) describe the ways in which technology (more generally) plays a significant role in the growth of incubated startups. Among these 36 managers, 7 $(19 \%)$ identified themselves as "technology" or "high-tech" industry incubator managers. Within this group, specialized lab equipment and facilities were generally emphasized as being of the most crucial importance to 
incubated start-ups, and these were often the only types of technology discussed. In these cases, the concept of location was more important. One additional respondent expressed an inability to adequately answer the question on the assumption that such "specialized" equipment was what was meant by "technology," stating that "most of our 'technology-oriented' businesses provide their own specialized technology and software, etc." The remainder of this analysis will bracket all 8 of the responses just described as being a general indication that technology-based research and development, and the facilities, equipment, and support required for those activities, are central to the start-up and incubation in certain industries. Among the 29 respondents who provided answers related to business versus industry/product technologies, 28 (97\%) mentioned the Internet and/or Internet-based tools. Many respondents specifically emphasized the value of "WIFI" and various wireless online platforms. The most frequently mentioned technologies were those associated with communication and especially those in the realm of collaborative technology, which appeared in 14 of the 29 pairs of responses. In this category, references to forms of Web and video conferencing and similar VOIP technologies, such as "webinar or virtual meetings," and "GoToMeeting" were especially common (listed by 6 of the 14 responses in this group). Other respondents mentioned "smart phones," "mobile devices," "email," "social media," or, more generally "collaboration technologies." The information technologies were noted by 8 of the 29 managers' (28\%) responses to these two questions. In this category, respondents referred to "IT services,"“file storage/sharing," and "the ability to process, maintain, and track pertinent business information using computer technology." Lastly, 6 of the 29 managers referred to the "online presence" of many incubated startups for the purposes of marketing and sales. One manager noted that "technology has allowed today's entrepreneurs to operate in a virtual state for longer, thus helping reduce costs in the early stages." Another indicated that because of the low overhead associated with such "virtual" operations, "most of the startups are dependent on the Internet for their business" and "for some, the Internet is their business." A number of general references were also made in the use of online marketing, advertising, and promotion platforms. With reference to the former (co-location), the respondents were asked to rate the importance on a four-point ordinal scale from "very important" to "not important" (and responses ranged across all four responses). More than half (57\%) of the surveyed incubator managers indicated that co-location was "very important", (see Figure 8). Nevertheless, it is worth noting that there a was considerable overall division on this question, with $15 \%$ rating co-location "important," $19 \%$ deeming it only "somewhat important," and a surprising 9\% asserting that co-location was "not important." This suggests a considerable degree of openness among a significant population of incubator managers to off-site alternatives.

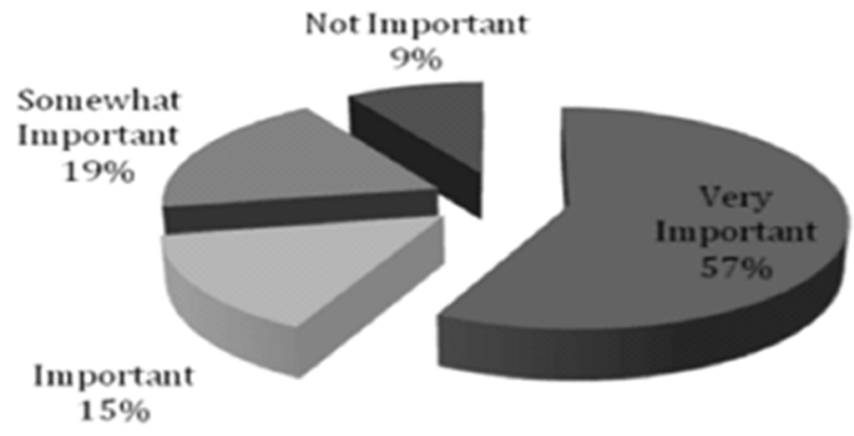

Figure 7. Importance of Co-Locating in an Incubator Program

\section{Summary Profile}

A preliminary profile was established based on the responses of the managers of present day incubators. The generalizability of this initial profile was limited due to the small sample size and the exploratory nature of this study. However, creating a picture of business incubators may help people understand the current trends and directions and possible future applications. Below are the relevant points gathered.

\subsection{Clients}

- Fifty-nine percent (59\%) of the incubator managers surveyed are serving small businesses.

- Thirty-one (31\%) are serving students.

- Larger incubators are more likely than small incubators to serve students. 
- Eighty-nine ( $89 \%)$ of the manager see clients as being risk takers, but not adversely so.

- Sixty-six (66 \%) see their clients as being able to adapt; those who are risk takers are also likely to be seen as adaptive.

- Crucial traits for success include:

Overcoming challenges $(63 \%)$

Risk taking (44\%)

Organizational and leadership skills (20\% and $24 \%)$

\subsection{Mission}

- Fifty-nine (59\%) have a mission statement with $65 \%$ stating that it is extremely clear.

- Ninety-eight (98\%) stated that their business plan supported the mission statement.

\subsubsection{Staffing}

- $\quad$ Ninety-three (93\%) are qualified to operate an incubator.

- Ninety-four percent (94\%) are highly qualified to lead a business.

- These traits are desirable for business incubator personal take on both roles in equal measure. This is especially true of business incubator managers.

\subsubsection{Services}

- Advisory role rates at $61 \%$ in importance. This is rated speed up the learning process by $98 \%$.

- Incubates learned new skills by $49 \%$ when they agreed to undertake incubator services.

- Thirty-eight percent (38\%) held that business incubators provided an important reality check for business situations.

\subsubsection{Management}

- Client services and organizational management accounts for the two main occupations of incubator managers.

- For client services, a great number of incubator managers spend $70 \%$ of their time in direct client services such as mentoring, advising, and counseling. The other $49 \%$ is spent on indirect services such as setting up meetings, networking and the like.

- For organizational management, day-to-day task handling and implementation assistance accounts for $65 \%$ of management services provided by incubator managers.

\subsubsection{Facilities/Technology}

- Eighty-three percent (83\%) mentioned office location as significant.

- Administrative services and facilities rates $65 \%$ while mentoring rates $59 \%$.

- A great percentage seems to focus on current day technologies with an overwhelming $93 \%$ stating internet services as paramount.

The resources that are worth noting are $74 \%$ phone systems, web hosting $24 \%$, accounting $15 \%$ and legal $19 \%$.

\section{Discussion and Conclusions}

The purpose of this study was to describe the historical evolution of business incubators in the United States from 1959 to the present day. Data were gathered on the business characteristics deemed critical to success such as corporate mission, plans and strategies, leadership/management, staff competence and expertise, facilities and resources and technology. A mixed methodology was used to collect and analyze data that addresses this purpose, utilizing both historical and survey research methods. 


\section{Findings (Summary):}

\subsection{Historical}

The historical study traced the growth and development of business incubators from the time period following World War II to the present time. The idea of nurturing a business in its formative stage, much like an incubator aid a newborn child was the core idea of business incubators from its early stages and is still relevant today. While each of the three generations of business incubators had its own peculiar challenges and developmental pains, it was remarkable to note that some aspects still remain the same.

\subsection{Mission}

What was apparent in the first generation of business incubators, from 1959-1979, was the direct response of business incubators to the lean and difficult war years. New ideas abounded and incubators were there to help these new ideas flourish. This was not surprising given the human need to rise and focus energies on endeavors that would improve over-all quality of life. Starting small businesses seemed to be a veering off from the big government contracts and companies characteristic of the war years. Business incubators during this period had a simple mission: improve economic conditions post-war. Universities led this resurrection, in consort with government bodies (Adkins, 2002).

The mission of third generation incubators, from 2000-2012, developed into providing professional business services of increasing complexity. Partnerships with universities continued to be strong, although the focus of this partnership has expanded to address current issues such as intellectual property rights, licensing, laws, government regulation and technology (Santoro \& Betts, 2002).

\subsection{Personnel}

In the first cohort period, these experts helped counsel and train individuals and business owners. It eventually became formal with the establishment of a volunteer counseling and training program for small industries (Willing, 1982). In the second generation, this volunteer program was on-going and underwent more refinement. In the third and current generation, business incubators have progressed in terms of organizational structure. They now consist of an executive and advisory board, a CEO or operations manager and support staff. In essence, it is now more formal. Therefore, its personnel structure has likewise become more institutionalized (Zablocki, 2007).

Another striking quality of the present business incubators was the heightened atmosphere of co-learning among leaders, staff, business incubators, and other fellow entrepreneurs (Zablocki, 2007).

\subsection{Resources}

From 1959-1979, business incubators provided the most basic facilities. This consisted of nothing more than low-cost space rentals to aid new business ventures. Business incubators also supplied a few services such as clerical and management training (Barrow 2001; Lalkaka \& Bishop, 1996). Today, facilities and services of business incubators have become multidimensional and complex. In this third generation, the rise of virtual connectivity has negated the strict need for co-location. Many options have opened for small businesses with higher standards of help and service provided by modern business incubators (Aerts, Matthyssens \& Vandenbempt, 2007; EC, 2002; McAdam \& McAdam, 2008).

\subsection{Technology}

The first generation of business incubators had office space rentals and whatever hardware was available in this era. Technological innovation for business was in its seed phase and would develop in later times. The second generation began to experience an increase in various technologies that influenced how small businesses communicated with other businesses and how they managed the operations of their businesses (Lalkaka, 2006).

\subsection{Served Client's Profiles}

Data collected from the survey could be open to different interpretations given that many questions on the survey were open-ended in format. My interpretation is in accordance with my background as an academic and practicing entrepreneur. The "temperature taking" or exploratory nature of the questions included on this survey provided but a general overview of what might be happening among today's business incubators. The profile that follows begins with a background on clients served by business manager respondents. This is followed by a description of the process of "incubating," that centers on services provided, facilities and resources needed, and the impact technology has had on how small business and incubators carry out their work. 


\subsection{Client's Served}

The two most commonly cited "pre-incubation occupations" of clients served by manager respondents were "small business owner," followed by "student." These two occupations comprised about two-thirds of clients served. Other clients served include non-business clients and non-students, each of which represented less than $15 \%$ of the responses. Being a small business owner as a "pre-incubation occupation" suggests these clients had prior experiences in business practices and may be involved in the incubator process due to a new or innovative business endeavor. My experiences as an incubator manager and as an entrepreneurial small business owner has helped me understand the importance of being involved in an incubator when significant changes in business mission and productivity occur; innovation requires new, innovative business practices.

\subsection{New Mindsets}

Managers who responded to the survey identified new mindsets they center on as they work with clients in developing their entrepreneurial business. One mindset centers on comprehending the issues or details involved in developing and growing a business. For some clients, what is needed is a "reality check" that moves clients from being overly confident toward an understanding of not only how to build a new product and run a business, but of the "real" challenges one might face in the process. This requires attention not only to the details but to big picture views of their business and how it might be situated in today's markets.

Adaptability is another mindset incubator manager stressed as being important to run a successful small business in today's world. Being adaptive means paying close attention to what is happening in one's business in the other related business endeavors. I have witnessed many changes in businesses over the years and see change today is happening at a fast pace, especially as new technologies continue to evolve and the markets are increasingly global in nature. I have learned that what was good yesterday may not be good for today or tomorrow. A majority of the managers viewed their clients "high" in adaptability.

\subsection{Incubation Process (Profile)}

\subsubsection{Mission}

The vast majority of managers who responded to the survey indicated they had a mission which was clearly stated and used for strategic planning for the incubator. Of interest in this study was how managers spent their time working with clients.

\subsubsection{Services Provided}

Incubator managers indicated that they spend much of their time providing what I called "direct services" to clients. Direct services mentioned by managers included "mentoring," "training," "counseling," helping, and "working with" clients. The indirect services included networking activities, establishing partnerships, locating resources, managing and searching for strategic relationships with external parties, identifying economic partners, facilitating meetings with potential advisors, investors, and mentors. All of these indirect services were considered by managers to assure the success of their clients. Operational management also was a service manager addressed in the survey as being important to clients having a successful incubator experience.

\subsubsection{Staffing}

Managers perceived their staff was highly qualified to both manage and run the incubators and to provide clients necessary services. Nearly all of the managers rated their staff as being "highly" or "very" qualified to engage and assist clients.

\subsubsection{Facilities}

The incubation process was a combination of providing both services and facilities for clients. Space was considered to be important to managers to carry out their work with small businesses since the space and corresponding resources can provide a climate for learning and growing. I have found that space needs to be convenient for clients and include amenities needed to learn and grow.

\subsubsection{Technology}

It is undeniable that advances in computing technology and the Internet have changed how we communicate nowadays. From high-powered computers to mobile devices such as Smartphones and Notebooks, these pieces of technological advancement have all contributed in making the way we interact more efficiently. As business is actually a process of interaction between a provider of goods or services to a buyer, it is safe to say that the more effective the communication channel is, the more successful the interaction will be. As such, the survey took into 
account how technology factors in the success of a business start-up.

\section{Conclusions}

- Generationally, incubators have attended to the historical, social, and economic contexts of the times, with their mission being centered on helping the nation and businesses find economic success. Innovation, or the entrepreneurial spirit, has been a foundation for business incubators over the years.

- Personnel connected to the business incubators have been connected to "experts" in the field to assure services provided are most helpful and up to date. Personnel have tended to have a rich background in small business and entrepreneurial thinking.

- Partnerships, collaboration, and networking have been key values inherent in incubators across the generations. Partnerships and collaborative efforts have been established with universities and with businesses both locally and globally. Networking is seen as a way to connect small businesses with related businesses to help guide entrepreneurial efforts.

- Business incubators focus on changing mindsets, helping clients gain knowledge and skills regarding how to operate a business and how to think about and react to challenging circumstances. Risk-taking and adaptation are two important characteristics of mindsets needed for success in today's world.

- Today's incubator managers provide important services to clients. Direct services involve mentoring, training, consulting, and advising. Indirect service centers on setting up partnerships and networking opportunities and facilitating meetings that can benefit clients' futures. Operational management services center on managing facilities and operating the incubator to ensure a clear focus and direction exist.

- Facilities and resources are important for incubators provide needed services. The facilities need to meet the needs of clients, and resources need to be available to ensure clients are able to grow and develop.

- Technology has changed over the years, but has always been integral to the operation of business incubators. Modern day technology is important to entrepreneurial small businesses, especially as it relates to communication within and between businesses. As well, technology plays an important role in how small businesses manage data bases critical to monitoring progress.

- The question of the usefulness of virtual incubators has arisen. While initially appearing to be the ultimate cost reducing solution that negates the need for co-location, the benefits derived from the physical interaction between incubator managers, incubates, experts and peers seems to outweigh the virtual option. Even with present day technology that has made this viable, virtual incubation may not be the perfect alternative it was once thought to be.

\section{Discussion}

In undertaking the historical study of business incubators, one striking realization was that this basic concept emerged due to important situational and contextual forces. In the immediate years following World War II was a critical period of economic development.

During this period, growth and job creation were of paramount importance. Clarke and Gaile (1992) characterized this era as one where risk-taking approaches were encouraged. So enter the entrepreneurial spirit of business incubation and one can see the germ of an idea worthy of the times it was conceived in. Fast forward to current realities and the spirit of innovation is still entirely evident in the newer business incubation models.

So "Being together within the same physical space can foster partnerships among startups, facilitating the flow of knowledge and forging of marketing and technology relationships among them". Hackett and Dilts (2004) went as far as stating that if virtual incubators are to be credited in the same level as business incubators, it follows then that any other business providing some type of assistance to other enterprises can be classified as incubators. Although the research explains that the majority of the incubator managers showed reluctance to making a move toward a virtual environment, this likely will become more and more advantageous as technology improves with the emergence of more technically collaborative tools. Eventually technology may demonstrate the ability to connect individuals in different ways, giving them advantages that a traditional incubator might not provide. 


\section{Further Study (Recommendations)}

From a professional and personal perspective, the following may be examined to further our understanding of business incubators:

- While other business fields have extensively covered the concept of mission, there did not seem to be the same type of "concreteness" in defining and carrying out this idea in business incubators. Researchers interested in delineating the mission of business incubators and relating it to particular entrepreneurial businesses may find this extremely interesting.

- The significance of the role played by incubator managers was underscored in the present study. Current focus on the personnel of business incubators, particularly the management and leadership, may be undertaken. This could include a complete management and leadership profile with concomitant success or failure factors.

- The trend towards partnerships, collaboration and networking in $21^{\text {st }}$ century business settings was reiterated for business incubators. Two types of research are envisioned: (a) the people component interaction between incubators and incubates; and (b) the effects of improved technology and resources as facilitating factors for increased collaboration.

- Virtual incubation emerged as an enigma in the present study. The viability of this option cannot be completely abandoned and must be studied further.

- Merging two ideas, changes in technology may necessitate that future managers have the ability to manage people within complex virtual environments. New studies on this interface may be indicated. The question of whether traditional styles, skills and strategies for business incubator managers will work within a virtual environment or whether a paradigm shift is necessary would be a stimulating concept for analysis.

- A creation of a complete incubate profile is of personal interest to me. As a researcher, the lack of information specifically on business incubators was evident. While this study sought to fill this gap, it was not exhaustive. Future studies may be needed.

- Since business incubation has reached a greater degree of maturity from its original inception, it may be timely to compile a manual of best practices in all the business characteristics mentioned. Likewise, models for successful business incubation can be created and validated in future studies.

\section{Reflections (Finalized):}

It was fascinating to see the way we conduct business today. It was hardly imaginable two decades ago that the world's largest businesses today would be comprised of entities like Google ${ }^{\mathrm{TM}}$, Facebook ${ }^{\mathrm{TM}}$, Yahoo ${ }^{\mathrm{TM}}$, and Ebay ${ }^{\mathrm{TM}}$, the main asset of which is a dominant online presence on the Internet. With all of the emphasis on a business's "virtual presence," it follows that the next stage of progression in mentoring incubates would be a virtual form of mentorship. A study has shown that incubator managers believed that having the right traits in an incubator was still critical for the success of a business start-up. No amount of capital or technological tools can replace competent management. Looking at this idea, it is important to realize that people are as essential to the process. Research has shown that Small Business Incubators (SBIs) have changed in the last fifty years since their inception. With technology, we have seen these incubators move toward using new tools and establishing a different way to interact with each other and the management. As this technology continues to advance, we will soon see more and more advanced virtual incubators with capabilities that exceed anything that is currently being done today. Based on the results of this research and the incubator managers' reluctance to use this form of incubator as a strong option now, this change will likely take place if and when technology is able to effectively replicate the human interaction.

\section{References}

Adkins, D. (2002). Brief history of business incubation in the United States. Athens, OH: NBIA Publications.

Aerts, K., Matthyssens, P., \& Vandenbempt, K. (2007). Critical role and screening practices of European business incubators. Technovation, 27(5), 254-267. https://doi.org/10.1016/j.technovation.2006.12.002

Barrow, C. (2001). Incubator: A Realist's Guide to the World's New Business Accelerators. West Sussex, UK: John Wiley \& Sons Ltd. 
Clarke, S., \& Gaile, G. (1992, May). The next wave: postfederal level economic development strategies. Economic Development Quarterly, 6(2), 187-198. https://doi.org/10.1177/089124249200600207

EC. (2002). Benchmarking of Business Incubators, Final Report. Brussels, Belgium.

Hackett, S. M., \& Dilts, D. M. (2004). A systematic review of business incubation research. The Journal of Technology Transfer, 29(1), 55-82. https://doi.org/10.1023/B:JOTT.0000011181.11952.0f

Lalkaka, R. (2006). Technology Business Incubation: A Toolkit on Innovation in Engineering, Science and Technology - Volume 255. Paris: UNESCO.

Lalkaka, R., \& Bishop, J. (1996). Business incubators in economic development - an initial assessment in industrialising countries. New York, NY: United Nation Development Programme.

McAdam, M., \& McAdam, R. (2008). High tech start-ups in University Science Park incubators: The relationship between the start-up's lifecycle progression and use of the incubator's resources. Technovation, 28(5), 277-290. https://doi.org/10.1016/j.technovation.2007.07.012

Santoro, M. D., \& Betts, S. C. (2002). Making industry-university partnerships work. Research Technology Management, 45(3), 42-46. https://doi.org/10.1080/08956308.2002.11671499

Willing, P. R. (1982). A history of the management assistance and educational programs of the Small Business Administration from 1953 to 1978. University Microfilms International.

Zablocki, E.M. (2007). Formation of a business incubator. Intellectual Property Management in Health and Agriculture Innovation: a Handbook of Best Practices. Retrieved from http://www.iphandbook.org/handbook/ch13/p06/\#11 MIHR: Oxford, U.K., and PIPRA: Davis, U.S.A. 